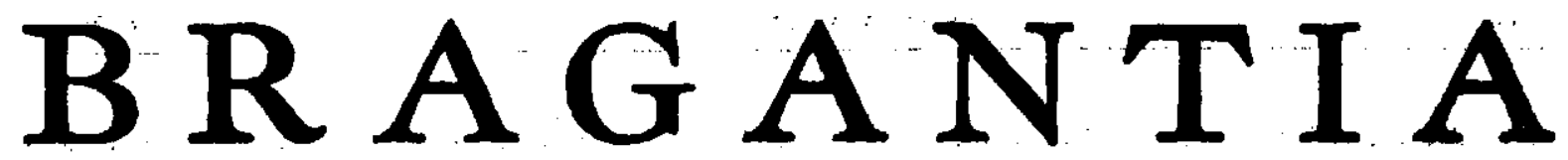

Boletim Técnico da Divisão de Experimentação e Pesquisas I N S TITUTO AGRONÓMICO

Vol. 2

Campinas, Abril de 1942

N. ${ }^{\circ} 4$

\title{
UMA FORMA GIGANTE EM Nicotiana tabacum L.
}

\section{A. Rodrigues Lima \\ e \\ R. Forster}

O aparecimento de tipos gigantes em culturas de fumo tem sido relatado por diversos autores. A primeira referência foi feita por Hunger (4), que, trabalhando com fumos em Delhi, diz ter encontrado excepcionalmente plantas gigantes, tendo uma delas atingido a $5 \mathrm{~m}$ de altura e produzido 123 folhas.

Garner e Brown (2) descrevem uma forma gigante, o Maryland Mammoth, produzindo geralmente mais de 100 folhas.

Hayes (3) relata o aparecimento de um fumo gigante, inicialmente encontrado em 3 plantas, em uma cultura de fumo Connecticut Cuban, produzindo, em regra, de 70 a 80 folhas, e ao qual chamou "Stewart Cuban".

Allard (1) refere-se a um tipo gigante encontrado na segregação de progênies de um cruzamento entre Nicotiana tabacum e $N$. sylvestris.

Tukada e outros (6) referem-se ao aparecimento espontâneo de formas gigantes em variedades indígenas de fumo. Cita a variedade "Ensyûha", no Japão, com caraterísticas do tipo gigante.

Num campo de cultura de progênies de fumo, variedade Virginia Bright, plantado na fazenda Santa Elisa, em Campinas (5), com 6 anos de autofecundação, encontramos 3 plantas, na progênie n. ${ }^{\circ} 555$, que até agosto não haviam florescido, continuando a vegetar, ao passo que todas as outras haviam florescido em meados de máio.

$\mathrm{Na}$ pressuposição de que não chegassem a florescer, retiramos das citadas plantas um certo número de brotos, os quais cresciam vigorosos na parte superior das mesmas, e plantamos em canteiros como estacas. Dezoito desenvolveram-se bem e deram plantas que floresceram em fins de outubro do mesmo ano. O florescimento foi um tanto esparso, não havendo formação de grandes inflorescências.

Semeados em dezembro de 1939, juntamente com a variedade Virginia Bright, germinaram e desenvolveram-se no canteiro de maneira aparentemente idêntica d̀ daquela variedade, alcançando o tamanho 
de transplante na mesma época. Transplantados, em começo de fevereiro (dias 8 e 10), para o campo, confirmaram seus caracteres, reproduzindo o tipo gigante cujo florescimento só teve lugar nos últimos dias de agosto. A variedade normal iniciou o florescimento 56 dias após o transplante, ou seja com quase 4 meses de antecedência.

Quanto ao tipo da planta gigante, é muito semelhante ao da variedade normal no seu primeiro período de crescimento: as mesmas dimensõ̇s, coloração, posição e forma de folhas. Internódios um pouco mais curtos e brotação menor em alturas correspondentes nas duas plantas. Com o prosseguimento da vegetação, vão-se acentuando as diferenças: as folhas inferiores na forma gigante teem uma tendência para decair precocemente, sem mesmo completar a maturação, ou amadurecer precocemente e em seguida começar a amarelar e secar, numa crestação que vai invadindo toda lâmina e atingindo folhas gradativamente mais altas. (Fig. 1).

$\mathrm{Na}$ parte superior desenvolve-se forte brotação, mais acentuada que na variedade normal.

O florescimento é fraco. A inflorescência é reduzida, não tendo sido observado número superior a 4 flores. Estas são em tudo normais, porem, com uma produção de sementes em geral menor que na variedade normal.

Nenhuma observação foi feita até o presente quanto a suas vantagens como produtoras de folha, seja para cura em estufa, seja para cura natural de galpão (flue-curing or air-curing).

Como as outras formas gigantes, apresenta de início o inconveniente de exigir um período muito longo de colheita, em consequência da maturação gradual prolongada das folhas, de baixo para cima.

Para estudo do comportamento genético do carater gigante, fizeramse diversos cruzamentos com a variedade normal, os quais já se acham no campo.

\section{S U M M A R Y}

A giant type of tobacco, Nicotiana tabacum L., spontaneously appeared in a tobacco culture at the Central Experiment Station, Campinas, during the agricultural year 1938-39.

Cuttings from three of those plants were grown to maturity and seeds were secured from 18 of them. All the seed reproduced the giant type.

\section{LITERATURA CITADA}

1. Allard, H. A. Gigantism in Nicotiana tabacum and its alternative inheritance Amer. Naturalist 53:218-233. 1919 .

2. Garner, W. W. e D. E. Brown. Types and varieties of Maryland tobacco. Mar. Agr. Exp. Sta. Bul. 188:135-152, fig. 1-4. 1914.

3. Hayes, H. K. Tobacco mutations. Jour. Hered. 6:73-78. fig. 12-13. 1915.

4. Funger, F. W. T. Untersuchungen u. Betraichtungen ueber die Mosaikkrankheit der Tabakpflanze. Zeits. Pflanzenk. 15:257-311. 1905.

5. Lima, A. Rodrigues. Relatório da Secção de Fumo, ano agrícola 1937-38 : 1.17. (Não publicado ainda).

6. Tukada, $\mathbf{H}$, e outros. Mutation and plant breeding in regard to the giant tobacco. Japan Jour. Bot. 2:42-43. 1923. 


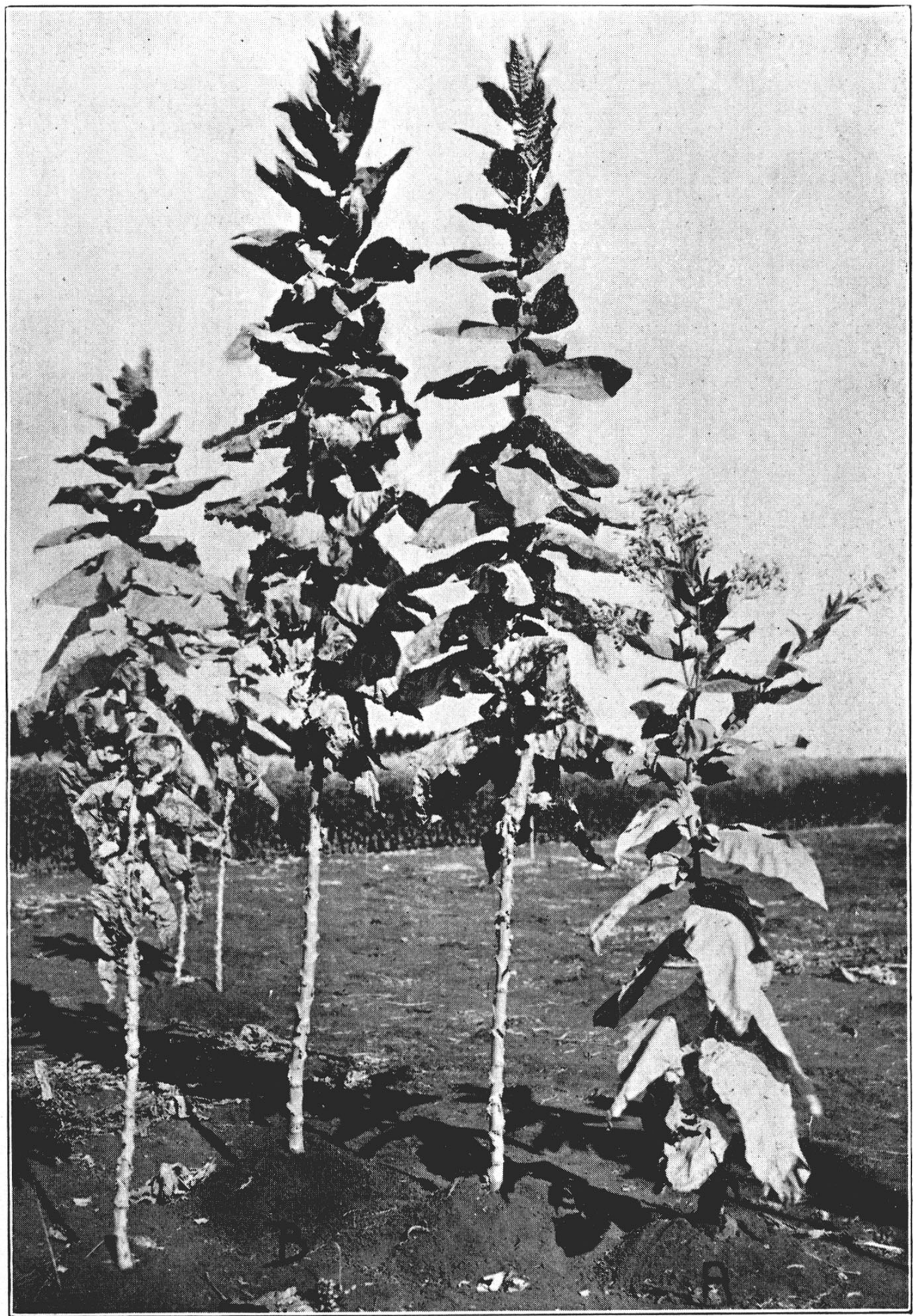

Figura 1. - Plantas de fumo gigante (B) ao lado de uma planta normal (A), var. Virginia Bright, progênie n. ${ }^{\circ}$ 3157. Fazenda Santa Elisa, 19.7.1940. 